\title{
BMJ Open ACTonDiabetes - a guided psychological internet intervention based on Acceptance and Commitment Therapy (ACT) for adults living with type 1 or 2 diabetes: results of a randomised controlled feasibility trial
}

\author{
Eileen Bendig (D) , ${ }^{1}$ Natalie Bauereiss, ${ }^{1}$ Andreas Schmitt (D) , ${ }^{2,3}$ Patrick Albus, ${ }^{1}$ \\ Harald Baumeister ${ }^{1}$
}

To cite: Bendig E,

Bauereiss N, Schmitt A, et al. ACTonDiabetes-a guided psychological internet intervention based on Acceptance and Commitment Therapy (ACT) for adults living with type 1 or 2 diabetes: results of a randomised controlled feasibility trial. BMJ Open 2021;11:e049238. doi:10.1136/ bmjopen-2021-049238

- Prepublication history and supplemental material for this paper is available online. To view these files, please visit the journal online (http://dx.doi. org/10.1136/bmjopen-2021049238).

Received 20 January 2021 Accepted 02 June 2021

Check for updates

(C) Author(s) (or their employer(s)) 2021. Re-use permitted under CC BY-NC. No commercial re-use. See rights and permissions. Published by BMJ.

For numbered affiliations see end of article.

Correspondence to

Ms Eileen Bendig;

eileen.bendig@uni-ulm.de

\section{ABSTRACT}

Objectives This two-group randomised controlled trial evaluates the feasibility of an Acceptance and Commitment Therapy (ACT)-based internet intervention for diabetes distress in people with diabetes type 1 or type 2. Participants were assigned to a guided self-help intervention (EG) or waitlist control group (CG).

Setting Recruitment took place following an open recruitment strategy including different diabetes centres, self-help groups and social media platforms.

Participants Eligibility criteria comprised being 18 years of age or older, self-reported diagnosis of type 1 or type 2 diabetes, internet access, sufficient German language skills and written informed consent.

Intervention ACTonDiabetes is an internet-based and mobile-based intervention and comprises an introduction and seven modules (one module per week, processing time about 45-60 min). Intervention contents are based on ACT.

Primary and secondary outcome measures Participants were assessed before and 8 weeks after randomisation. Primary outcome was feasibility (trial recruitment, acceptability). Potential group differences in diabetes distress and other outcomes at follow-up were analysed using linear regression models with baseline values as predictors. All analyses were based on an intention-totreat principle, potential negative effects were analysed on per-protocol basis.

Results From October 2017 to April 2018, N=42 people with diabetes consented and were randomised $(E G n=21, C G n=21)$. Forty-three per cent of the $E G$ completed all treatment modules within 8 weeks. Across modules, formative user feedback revealed that contents could be optimised regarding comprehensibility (34\%), individualisation (20\%) and text amount (21\%). Overall, $57 \%$ of participants dropped out prior to full treatment completion. There were reductions of diabetes distress in the $E G(d=0.65, p=0.042)$.

Conclusions Modifications of the intervention content according to the user feedback will be performed to further improve acceptability. Mechanisms to foster intervention
Strengths and limitations of this study

- This is the first trial on an Acceptance and Commitment Therapy-based internet intervention for people with diabetes.

- The intervention was adapted from a previously evaluated treatment concept for people with a chronic somatic disease.

- This feasibility trial promotes a responsible use of resources and a high standard of quality in a confirmatory trial.

- Attrition was high in both comparison groups.

- Formative user feedback is used to further improve the ACTonDiabetes intervention.

adherence should be considered for lowering the attrition rate. ACTonDiabetes is feasible for the implementation in a confirmatory trial.

Trial registration number WHO International Clinical Trials Registry Platform via the German Clinical Trials Register (DRKS) (DRKS00013193).

\section{INTRODUCTION}

The prevalence and incidence rates of diabetes are increasing worldwide. ${ }^{1}$ For Germany, there is an assumed increase of between 10.7 million $(+54 \%)$ and 12.3 million $(+77 \%)$ type 2 diabetes cases until $2040 .^{2}$ Additionally, the rate of individual years lived with diabetes is rising globally. ${ }^{1}$ Against the background of these developments, the editorial of The Lancet speaks of a 'diabetes pandemic'. ${ }^{3}$ Diabetes care constitutes an enormous economic burden for healthcare systems as well as an enormous burden on the level of individuals due to years lived with the disease. ${ }^{14}$ Living with diabetes type 1 or 2 is challenging. ${ }^{5}$ It comes along with a multitude 
of requirements that need to be considered and mastered in everyday life. ${ }^{5}$ Requirements comprise permanent self-treatment and monitoring, ${ }^{5-7}$ adhering to complex treatment plans, ${ }^{89}$ and promoting coping mechanisms to deal with diagnosis and disease. ${ }^{10}$ Consequently, the prevalence of diabetes distress is high. Diabetes distress is defined as experiencing negative emotions and burden due to the demanding and progressive conditions of living with diabetes. ${ }^{11} 12$ It involves negative emotional reactions ${ }^{5}$ such as feeling overwhelmed by the demands of living with diabetes, worries and fears about possible complications, frustration due to perceived limitations regarding lifestyle or suboptimal treatment outcomes. ${ }^{13} 14$ About $36 \%$ of people with type $2^{12}$ and $41 \%$ of the people with type 1 diabetes ${ }^{15}$ report elevated diabetes distress. This has consequences in many respects.

Diabetes distress has been associated with impaired psychological well-being, reduced treatment adherence, ${ }^{14}$ reduced glycaemic control $^{16}$ and common comorbid mental disorders like depression. ${ }^{17}$ In relation to this, a longitudinal study shows that diabetes distress can be associated with a higher incidence and persistence of depressive symptoms. ${ }^{18}$ Clinical treatment guidelines recommend the assessment of and interventions for reducing diabetes distress as integral part of diabetes care. ${ }^{19-21}$ However, elevated diabetes distress often remains untreated or undertreated due to various barriers. $^{20-22}$ Barriers include fear of stigmatisation, limited mobility of patients, time and resources as well as limited access and availability of psychological interventions. ${ }^{2324}$ Barriers can also arise on the part of healthcare professionals not detecting or being not able to address diabetes distress within routine consultations. ${ }^{25}$

Innovative technologies can help to overcome these barriers by delivering low-threshold digitised interventions on a large scale. ${ }^{26}{ }^{27}$ In this context, internet interventions have been considered a cost-effective and flexible approach to provide psychological interventions to people with diabetes. ${ }^{28} 29$ Internet interventions are (guided) self-help programmes which can be provided on a website ${ }^{30}$ and complemented with mobile-based applications like apps. ${ }^{26} 27$ Guidance refers to human support from e-coaches (eg, psychologist/physician). ${ }^{30}$ Evidence suggests that at least a minimum of guidance can constitute an effect-facilitating factor. ${ }^{31} 32$ A recent meta-analysis investigating internet interventions for people with mental disorders and/or chronic somatic conditions suggests that guided internet interventions can be as effective as traditional face-to-face interventions. ${ }^{33}$ Internet interventions have been effectively used to support behaviour change (weight loss, ${ }^{34}$ physical activity, ${ }^{35}$ glycaemic control, ${ }^{36}$ smoking cessation, ${ }^{37}$ alcohol consumption ${ }^{38}$ ). Additionally, they were effectively used for treating comorbid mental disorders in people with diabetes ${ }^{28} 39$ and clinically relevant diabetes distress. ${ }^{28} 29$ Nevertheless, overall evidence in the field is still very limited with regard to quantity and quality of studies. ${ }^{26}$ To date, interventional studies have not focused on diabetes distress as primary outcome in this field of research.

Nobis et $a t^{40}$ evaluated a guided internet intervention for people with diabetes type 1 or 2 with depressive symptom severity as primary outcome. Authors compared the treatment group with an active control group receiving psychoeducation. On the level of secondary outcomes of this trial, results indicated a significant effect of $\mathrm{d}=0.58$ (95\% CI 0.33 to $0.83, \mathrm{p}<0.001)$ for the reduction of diabetes distress post-treatment which persisted after 6 months $(\mathrm{d}=0.50,95 \% \mathrm{CI} 0.04$ to $0.54, \mathrm{p}<0.001){ }^{41}$ Likewise, van Bastelaar et $a t^{29}$ found significantly greater reductions of diabetes distress in the treatment group receiving internet-based depression treatment compared with a waitlist control group. The evaluated interventions were both based on cognitive-behavioural therapy (CBT)..$^{29} 40$

While most previously studied internet interventions are theoretically based on $\mathrm{CBT}^{42}$ people with chronic somatic conditions might benefit from interventions that focus less on aspects of 'change' and more on 'acceptance' of the unchangeable condition as in Acceptance and Commitment-based Therapy (ACT) ${ }^{43} 44$ ACT aims at increasing psychological flexibility by fostering acceptance of unchangeable aspects in life ${ }^{43}{ }^{44}$ like living with diabetes. ${ }^{45}$ Recent studies show positive effects of ACT in this population regarding self-management. ${ }^{45}{ }^{46}$ Gregg et $a t^{55}$ as well as Shayeghian $e t a t^{46}$ found that people receiving an ACT intervention performed better diabetes self-care and had more optimal glycated haemoglobin (HbAlc) values after the treatment than the active control group which received a structured education workshop on diabetes control. However, one study of Maghsoudi $e t$ $a l^{47}$ did not find significant reductions in diabetes distress following a group-based ACT intervention (eightweekly 90-minute sessions) in comparison with a treatment-asusual control group. Further studies are being initiated recently. ${ }^{48}$

To our knowledge, this is the first study on an ACTbased internet intervention aiming at reducing elevated diabetes distress. Notably, the effectiveness and costeffectiveness of the internet intervention 'ACTonPain' aiming at reducing pain-related burden in people with chronic pain were supported in studies by Lin et $_{\text {al }}{ }^{49-51}$ ACTonDiabetes was built on the ACTonPain treatment programme to develop a widely practicable, local and temporal flexible, low-threshold internet intervention to reduce diabetes distress in people with type 1 and type 2 diabetes.

The present study evaluates the feasibility of the programme ACTonDiabetes. Therefore, trial recruitment, acceptability and preliminary results regarding the effectiveness of the intervention are investigated. Results will inform decision processes concerning study procedures, potential amendments and the design of a future definitive trial. User feedback will be used to further improve and refine the ACTonDiabetes intervention. Specifically, this study aimed to: 
1. Explore the feasibility of trial recruitment and acceptability of the internet intervention.

2. Examine if the intervention potentially affects diabetes distress and other intended outcomes of a future fullscale trial.

\section{METHODS}

\section{Participants}

People were eligible to participate in this study if they were 18 years of age or older, had a self-reported diagnosis of type 1 or type 2 diabetes, had internet access, sufficient German language skills and provided written informed consent. Participants received the consent forms digitised or printed and were asked to sign and return them. Participants were excluded if they had other forms of diabetes (eg, gestational diabetes).

\section{Study design and assessment}

This parallel group, randomised-controlled feasibility trial enrolled participants from October 2017 to April 2018. The intervention group (EG) received the guided ACTonDiabetes intervention and was compared with a waitlist control group (CG) which started the unguided intervention 8 weeks after randomisation. This trial was conducted in accordance with the Declaration of Helsinki and good scientific practice. The present report follows the Consolidated Standards of Reporting Trials (CONSORT) 2010 guidelines for feasibility randomised controlled trials (RCTs). ${ }^{52}$

\section{Recruitment}

Recruitment took place following an open recruitment strategy. Different methods were administered: research staff in diabetes centres and diabetes self-help groups who informed potential participants of the offer, flyers in medical practices and social media posts in diabetesrelated groups. Interested people signed up on the ACTonDiabetes homepage or expressed their interest via email to the study mail address. Those who met the inclusion criteria and provided written informed consent were randomised.

\section{Randomisation and blinding}

Randomisation was performed on an individual level by a person not otherwise involved in the study (Lena Storz). The randomisation list was created by an automated webbased program called 'sealed envelope' (https://www. sealedenvelope.com). Lioba Fluhr enrolled the participants. A permuted block randomisation with variable 2 and 4 block size (randomly arranged) and an allocation ratio of 1:1 was used.

\section{ACTonDiabetes intervention}

The guided internet intervention was delivered on the online platform Minddistrict. The theoretical base is the ACT. Contents were adapted to the population of people with diabetes from the already evaluated ACTonPain intervention. ${ }^{49-51}$ The intervention consists of seven modules.
The content of the intervention involves psychoeducation underpinned by fictional peer support (a woman with recently diagnosed type 2 diabetes, a younger man with type 1 diabetes, an older man with long-standing, insulin-treated type 2 diabetes). The narratives of the peers address typical problems and burdens, worries, needs and experiences with strategies and resources as well as topics covered in the intervention. Contents are provided by means of texts, video sequences, audio files or illustrations of various ACT models and metaphors. A description of the intervention contents can be found in table 1. Participants are advised to process through the intervention in 7 weeks, completing one module per week. The processing time for each module is scheduled to take approximately $45-60 \mathrm{~min}$. ACTonDiabetes is based on three assumed effect factors: the intervention contents, guidance and daily exercises. Guidance was provided by an e-coach (psychologist) who provided standardised feedback after each module. To support transfer into everyday life, specific ACT-based exercises and tasks (eg, keeping a diabetes distress diary) were included. Furthermore, participants received short message service (SMS) coaching with motivational prompts and mindfulness tasks. A schematic depiction of the intervention can be seen in figure 1 .

\section{Measures}

All surveys were conducted online via the Unipark platform (unipark.de).

Measurement time points were at baseline (T1) and at 8 weeks after randomisation (T2) (ie, after the treatment should normally be completed). An overview of outcomes, measurements and points of assessment is shown in table 2.

Study aims were operationalised as follows:

1. Trial recruitment and acceptability.

- Access routes, study flow, baseline characteristics.

- User attitudes, formative user feedback, negative effects, adherence.

2. Potential of the intervention to affect intended outcomes in a confirmatory trial.

- Diabetes distress, depression, anxiety, selfmanagement, diabetes acceptance, quality of life, fear of progression.

\section{Trial recruitment and acceptability}

\section{Recruitment}

Access routes were recorded by an open-ended question asking how participants got to know about the study. With regard to study flow, early participant attrition was investigated to determine if mechanisms sufficiently bridged the gap between eligibility/consent and actual trial uptake, as recommended. ${ }^{53}{ }^{54}$ For this purpose, we measured the participation rate (number of participants divided by the number of eligible people). Recruitment was deemed successful if the participation rate was at least $70 \%$ of all eligible participants (in hoc sensu early attrition maximum $30 \%){ }^{54} 55$ In order to learn about 


\section{Table 1 Overview of contents and techniques of all sessions}

\section{Module Key module contents}

Focused ACT techniques

0 Introduction to the structure and basic ideas of the ACT training, explanation of $\quad$ Psychoeducation* sources and evidence

$1 \quad$ Fostering of treatment expectations and motivation, psychoeducation on diabetes and its complications, diabetes distress and associations between diabetes and mental health; development of the individual diabetes history and coping mechanisms; introduction to the ideas of ACT; elaboration of a good reason for processing through ACTonDiabetes; clarification of individual objectives for the training; introduction to mindfulness and conscious breathing; elaboration of the individuals' previous handling of diabetes distress, previous strategies with short-term and long-term success; presentation of possible different approaches alongside ACT

\begin{tabular}{|c|c|c|}
\hline 2 & $\begin{array}{l}\text { Introduction to the concepts of control and acceptance, development of the idea } \\
\text { of mindfulness: the body; introduction of the diabetes diary within which the focus } \\
\text { is on components of the SORC-mode }{ }^{95} \text { (Behavioral analysis model, acronym: } \\
\text { Situation, Organism, Reaction, Contingency/ Consequence); diabetes distress and } \\
\text { (un-)influenceable variables in life; primary and secondary suffering; introduction } \\
\text { to behavioural experiments, self-observation tasks, homework, ACT metaphors } \\
\text { and mindfulness exercises. Further optional diaries are offered to support self- } \\
\text { observational processes/tracking behaviour (eg, acceptance diary, mindfulness } \\
\text { diary) }\end{array}$ & $\begin{array}{l}\text { Experiential acceptance* } \\
\text { Recognising malfunctions of } \\
\text { control strategies; acceptance } \\
\text { as alternative concept }\end{array}$ \\
\hline 3 & $\begin{array}{l}\text { Elaboration of and differentiation between thoughts and feelings; development of } \\
\text { the idea of mindfulness regarding thoughts; dealing with negative thoughts and } \\
\text { feelings; language processes and vocabulary tips to support defusion processes }\end{array}$ & $\begin{array}{l}\text { Defusion, }{ }^{*} \text { recognising the } \\
\text { meaning of language; creating } \\
\text { distance from own thoughts }\end{array}$ \\
\hline 4 & $\begin{array}{l}\text { Self-conceptualisations; three senses of self; being the observing self; } \\
\text { development of the idea of mindfulness regarding all senses }\end{array}$ & $\begin{array}{l}\text { Self as context* } \\
\text { Defusing from implicit } \\
\text { evaluations; getting to know the } \\
\text { observing self }\end{array}$ \\
\hline 5 & $\begin{array}{l}\text { Introduction to values; values as chosen life directions; choosing values; goal- } \\
\text { setting strategies, mindfulness regarding feelings }\end{array}$ & $\begin{array}{l}\text { Values; }{ }^{*} \text { developing value } \\
\text { awareness }\end{array}$ \\
\hline 6 & $\begin{array}{l}\text { Commitment and its influence on a value-driven life, mindfulness in the everyday } \\
\text { life, ACT formula; begin to take action }\end{array}$ & $\begin{array}{l}\text { Committed action, ACT } \\
\text { formula; }{ }^{*} \text { learning ways to act in } \\
\text { accordance to values }\end{array}$ \\
\hline 7 & $\begin{array}{l}\text { Development of the way forward; commitment; conclusion and future perspective, } \\
\text { skills overview and maintenance }\end{array}$ & $\begin{array}{l}\text { Committed action, } \\
\text { mindfulness; }{ }^{*} \text { sustainable } \\
\text { anchoring of the learning } \\
\text { content in everyday life }\end{array}$ \\
\hline
\end{tabular}
Psychoeducation* Acceptance Generation of creative hopelessness

Every module starts with a review of key elements from the last session and ends with a summary and outlook.

*Inclusion of metaphors (eg, man in the fountain; playing tug of war with unchangeable aspects in life), tasks and exercises to make contents experienceable.

ACT, Acceptance and Commitment Therapy; SMS, short message service.

characteristics of the population reached by applied recruitment strategies, we assessed age, gender, diabetes type and former psychotherapy/counselling experience. Additionally, we explored if participants who signed up had a certain level of burden, thus elevated symptoms of diabetes distress, depression or anxiety at baseline (T1).

\section{Acceptability}

Acceptability refers to reactions of participants regarding the ACTonDiabetes intervention. ${ }^{56}$ Collected data include attitudes towards internet interventions (Attitudes towards Psychological Online Interventions Questionnaire $\left.(\mathrm{APOI})^{57}\right)$, as well as information acquired through the online platform Minddistrict on usage and engagement (number of modules completed, length of processing time per module, number of intervention completers and formative user feedback). Formative user feedback was collected to gain knowledge of the users' acceptance of the intervention. Therefore, we assessed comments and critiques of the participants as well as the perceived appropriateness of the intervention contents. Furthermore, we assessed perceived negative effects of the intervention (Inventory for the Assessment of Negative Effects of Psychotherapy (INEP) $)^{58}$ ), as well as treatment satisfaction (Client Satisfaction Questionnaire (CSQ-8 ${ }^{59}$ ) using validated questionnaires. 


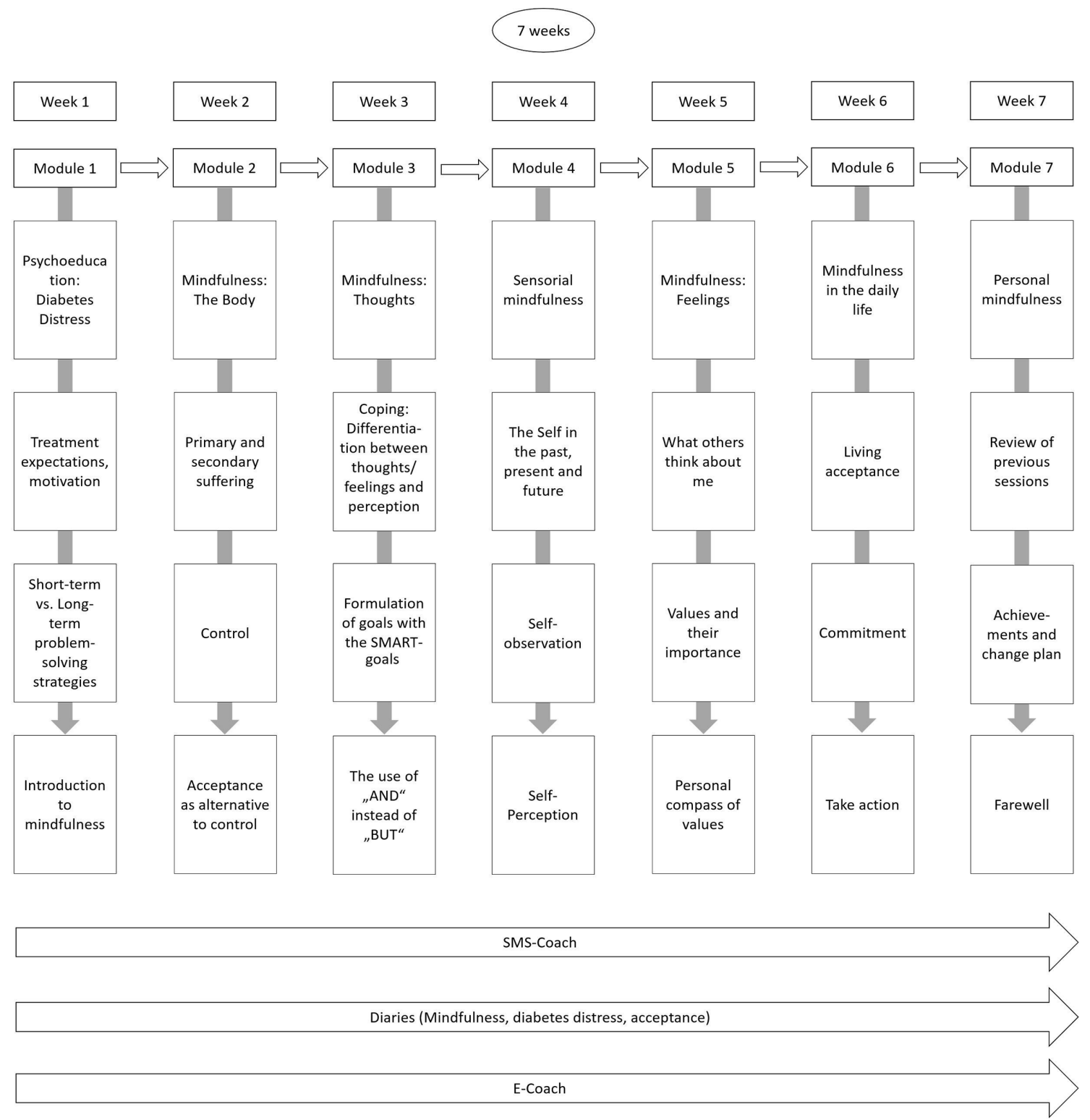

Figure 1 Intervention structure of ACTonDiabetes. SMS, short message service. SMART, specific, measurable, achievable, relevant, time-limited

\section{Attitudes towards internet interventions}

The $\mathrm{APOI}^{57}$ consists of 16 items (eg, 'I think ACTonDiabetes could help me') which are rated on a 5-point Likert scale ( $1=$ 'I do not agree at all' to $5=$ ='I agree completely'). The tool estimates four subscales (four items each): scepticism and perception of risks (SCE), threat due to technology (TET), confidence in effectiveness (CON) and anonymity benefits (ABE). Higher scores on CON and $\mathrm{ABE}$ indicate more positive attitudes, while higher values on SCE and TET indicate more negative attitudes towards internet interventions. Subscale scores can be added to a total score (range 16-80). A higher total score indicates a more positive attitude.$^{57} \mathrm{~A}$ low level of acceptance of the internet-based delivery format has been associated with a lower uptake rate. ${ }^{60}$ Thus, an at least medium level of acceptance may be required for the implementation on a larger scale. ${ }^{6162}$ Understanding attitudes towards internet interventions may help allocating dissemination and recruitment resources for a larger RCT efficiently. ${ }^{62}$

\section{Formative user feedback}

Participants in the EG received a voluntary feedback questionnaire after each module. Questions aimed at rating the length and comprehensibility for each module on a 3-point scale (too short, just right, too long). Additional open questions were administered to gather information on certain intervention contents (exercises, techniques or metaphors) per module ("What was the most/least helpful exercise for you within this module?').

\section{Negative effects}

Potential negative effects were assessed using the 15 -item version of the INEP. ${ }^{58}$ Participants rated possible negative effects which occurred during or 
Table 2 Overview of constructs, measurement instruments and points of assessment

\begin{tabular}{llll}
\hline & & \multicolumn{2}{l}{$\begin{array}{l}\text { Point of } \\
\text { assessment }\end{array}$} \\
\cline { 3 - 4 } Construct & Instrument & T1 & T2 \\
\hline Trial recruitment & & X & X \\
Recruitment strategy & & $X$ & $X$ \\
Demographics & Self-report & X & \\
Dropout & $\begin{array}{l}\text { Study attrition } \\
\text { rate }\end{array}$ & $\mathrm{X}$ & $\mathrm{X}$ \\
& & & \\
\end{tabular}

\begin{tabular}{|c|c|c|c|}
\hline \multicolumn{4}{|l|}{ Acceptability } \\
\hline Satisfaction & (CSQ-8) & $x$ & $x$ \\
\hline Negative effects & INEP & & $x$ \\
\hline $\begin{array}{l}\text { Attitudes and } \\
\text { expectations }\end{array}$ & APOI & $x$ & $\mathrm{X}$ \\
\hline Protocol adherence & $\begin{array}{l}\text { Treatment } \\
\text { dropout }\end{array}$ & & $x$ \\
\hline $\begin{array}{l}\text { Formative user } \\
\text { feedback }\end{array}$ & $\begin{array}{l}\text { Feedback per } \\
\text { module }\end{array}$ & & $x$ \\
\hline \multicolumn{4}{|l|}{ Outcome data } \\
\hline Diabetes distress & PAID & $x$ & $x$ \\
\hline $\begin{array}{l}\text { Depressive } \\
\text { symptoms }\end{array}$ & PHQ-9 & $x$ & $x$ \\
\hline Anxiety symptoms & GAD-7 & $x$ & $x$ \\
\hline Fear of progression & FoP-Q-SF & $x$ & $x$ \\
\hline $\begin{array}{l}\text { Acceptance and } \\
\text { Action Diabetes } \\
\text { Questionnaire }\end{array}$ & AADQ & $x$ & $x$ \\
\hline $\begin{array}{l}\text { Diabetes Self- } \\
\text { Management } \\
\text { Questionnaire }\end{array}$ & DSMQ & $x$ & $x$ \\
\hline Quality of life & AQoL-8D & $x$ & $X$ \\
\hline
\end{tabular}

T1=baseline; T2=post-measurement.

AADQ, Acceptance and Action Diabetes Questionnaire;

APOI, Attitudes towards Psychological Online Interventions

Questionnaire; AQoL-8D, Assessment of Quality of Life 8-item

Questionnaire; CSQ-8, Client Satisfaction Questionnaire; DSMQ,

Diabetes Self-Management Questionnaire; FoP-Q-SF, Fear of

Progression Questionnaire-Short Form; GAD-7, Generalized

Anxiety Disorder 7-item Scale; INEP, Inventory for the Assessment

of Negative Effects of Psychotherapy; PAID, Problem Areas In

Diabetes Scale; PHQ-9, Patient Health Questionnaire-9.

after the intervention on a 4-point Likert ( $0=$ "no agreement' to $3=$ 'total agreement') or a bipolar 7-point scale ( $-3=$ 'worse' to $3=$ 'better'). Participants then indicate if they attribute negative effects to the intervention or other circumstances (eg, 'I feel better $(+3)$...worse (-3) since the start of the intervention'; 'I put this effect down to the intervention' (1), 'other circumstances' (2)). Topics include possible negative effects in the fields social environment, intrapersonal factors and work-related situations.

\section{Treatment satisfaction}

The CSQ- $8^{59}$ measures satisfaction with the intervention using eight items and a 4-point Likert scale. Higher scores indicate higher treatment satisfaction. For psychosomatic populations, a mean of $\mathrm{M}=23.5$ ( $\mathrm{SD}=5.0){ }^{63}$ Thus, values close to $\mathrm{M}=23.5$ were classified as sufficient satisfaction with the ACTonDiabetes treatment to be investigated in a larger trial.

\section{Adherence}

Study attrition as well as intervention adherence was evaluated 8 weeks after randomisation. Adherence was operationalised by the percentage of participants who completed the majority of modules. That is, participants at least processed through the introduction and the initial four of the seven core modules within 8 weeks.

\section{Outcome data}

\section{Diabetes distress}

The 20-item Problem Areas In Diabetes (PAID) Scale ${ }^{64}$ was used to measure diabetes distress. The scale requests diverse emotional problems due to living with the chronic condition. Responses are given on a 5-point Likert scale ( $0=$ 'no problem' to $4=$ 'serious problem'). The raw sum score is multiplied with 1.25 to calculate the total score (range 0-100). Higher scores indicate higher diabetes distress. Values of 40 and above are considered to indicate elevated, thus clinically relevant diabetes distress. ${ }^{65}$

\section{Depression}

The Patient Health Questionnaire-9 (PHQ-966) was used to measure symptoms of depression. Its nine items assess the key symptoms of depression according to the Diagnostic and Statistical Manual of Mental Disorders; responses are given on a 4-point Likert scale $(0=$ "not at all' to $3=$ ='almost every day'). The total score ranges from 0 to 27 with values of 10 or higher suggesting elevated depressive symptoms.

\section{Anxiety}

The Generalized Anxiety Disorder 7-item Scale (GAD$7^{67}$ ) was used to measure symptoms of anxiety. Seven items are rated on a 4 -point Likert scale $(0=$ 'never' to $3=$ 'almost every day'). Higher total scores (range 0-21) indicate higher levels of anxiety.

\section{Self-management}

Overall, diabetes self-management was measured using the Diabetes Self-Management Questionnaire $\left(\mathrm{DSMQ}^{68}\right)$, consisting of 16 items which describe aspects of selfmanagement. Items are rated on a 4-point Likert scale $(0=$ 'does not apply to me' to $3=$ ='applies to me very much') . The raw sum score is transformed to a scale from 0 to 10 with higher scores suggesting better self-management.

\section{Acceptance}

The Acceptance and Action Diabetes Questionnaire ${ }^{69}$ was used to measure diabetes acceptance. Acceptance of diabetes-related feelings, thoughts and its impact on 
valued action is measured on 11 items on a 5-point Likert scale ( $1=$ ='never' to $5=$ 'nearly always').

\section{Quality of life}

The Assessment of Quality of Life 8-item Questionnaire ${ }^{70}$ was used to measure quality of life on eight dimensions (independent living, senses, pain, mental health, happiness, self-worth, coping and relationships). Sum score measures indicate overall physical and psychosocial quality of life. The total scores range between 35 and 176 points with higher values indicating higher quality of life.

\section{Fear of progression}

The short form of the Fear of Progression Questionnaire ${ }^{71}$ measures worries and fear regarding disease progression and development of diabetes complications using 12 items and a 5-point Likert scale ( $1=$ "never' to $5=$ "very often'). The total score ranges from 0 to 60 , higher scores indicate higher fear.

\section{Sample size}

As this trial was intended to help revise/finalise the intervention and select suitable outcome measures for the fullscale trial, the target of this trial was to recruit at least 40 participants with 20 participants per arm. In accordance with the extended version of the CONSORT statement for feasibility trials ${ }^{52}$ investigators decided to proceed with the recruitment of participants until enough information was reached to decide whether or how to continue with a future definitive trial. Online supplemental table 1 comprises formal feasibility criteria with regard to trial recruitment, acceptability and outcome data following standard recommendations. ${ }^{56} 72$

\section{Data analysis}

The data were analysed with R. ${ }^{73}$ Quantitative data include descriptive statistics (frequency, percentage, mean, SD, median) and linear regression models for investigating potential group differences. Regression models were used to investigate group differences (dummy coded predictor: $\mathrm{EG}=1$ ). Baseline values were used as covariate in all regression models. ${ }^{74}$ Analyses are based on an intention-to-treat principle. Multivariate imputation by chained equations were performed to create 20 complete datasets. ${ }^{74}$ Missing data were assumed to be missing at random. ${ }^{75}$ Predictive mean matching was used as imputation method. ${ }^{74}$ Imputation models were defined following the recommendations by van Buuren et al, ${ }^{74} 76$ that is, including variables defined for the primary analysis and auxiliary variables. Analyses were conducted for each imputed dataset and pooled using Rubin's rule. ${ }^{77} 78$ For all outcomes, mean, $\mathrm{SD}$, standardised regression coefficient and the corresponding $95 \% \mathrm{CI}$ are reported. The significance level was set to $\mathrm{p}<0.05$ for all analyses.

\section{Patient and public involvement}

Patient and public involvement (PPI) representatives provide input to the present study in several stages. The intervention was further developed in a multidisciplinary team comprising psychologists, psychotherapists, diabetes specialists and people with diabetes. PPI representatives were included in the intervention development to improve content, usability and design of ACTonDiabetes.

\section{RESULTS \\ Trial recruitment and acceptability \\ Recruitment}

The study was closed after $\mathrm{N}=42$ participants had been randomised. $\mathrm{N}=61$ individuals were assessed for eligibility and informed about the study. $\mathrm{N}=18$ people did not consent, two participants were excluded for not meeting inclusion criteria (figure 2). Forty-two people with diabetes were randomised (participant flow, figure 2), equalling to a participation rate of $71 \%$. Sixtyfour per cent of people assessed for eligibility got to know about the study from specialised diabetes centres, $30 \%$ were recruited via social media, $6 \%$ from other sources.

Baseline participant sociodemographic and clinical characteristics are presented in table 3. Mean age of the sample was $\mathrm{M}=46.9$ ( $\mathrm{SD}=14.4), 50 \%$ were female. The majority, $76 \%$, of the participants were diagnosed with type 1 diabetes.

Baseline diabetes distress was elevated with a mean PAID score of $\mathrm{M}=43.9$ ( $\mathrm{SD}=13.7)$. Furthermore, the mean PHQ-9 and GAD-7 scores at baseline suggested mild depressive $(\mathrm{M}=8.40, \mathrm{SD}=5.11$; $\mathrm{PHQ}-9)$ and anxiety symptoms $(\mathrm{M}=6.62, \mathrm{SD}=4.34$; $\mathrm{GAD}-7)$.

\section{Acceptability}

\section{Attitudes towards internet interventions}

The assessment of attitudes towards internet interventions using the APOI revealed values of $\mathrm{M}=39.7(\mathrm{SD}=7.1)$ at $\mathrm{T} 1$ and $\mathrm{M}=41.7(\mathrm{SD}=11.25)$ at $\mathrm{T} 2$ in the $\mathrm{EG}$, and $\mathrm{M}=40.1(\mathrm{SD}=9.4)(\mathrm{T} 1)$ and $\mathrm{M}=42.6(10.0)(\mathrm{T} 2)$ in the $\mathrm{CG}$ (see table 3 ). Attitudes were not significantly different between EG and CG at post-measurement $(b=-0.04$, $\mathrm{p}=0.86$ ). Participants' mean satisfaction with intervention according to the CSQ-8 total score was $\mathrm{M}=25.8(\mathrm{SD}=5.6)$ (table 3).

\section{Formative user feedback}

We received $\mathrm{N}=89$ feedback forms from $\mathrm{n}=21$ participants across the seven modules regarding processing time per module. Much feedback $(75 \%, \mathrm{n}=16)$ indicated that the processing time per module was just right. Minddistrict data revealed that processing through modules took on average $\mathrm{M}=84 \mathrm{~min}(\mathrm{SD}=36)$ per module. Open questions revealed that mindfulness and acceptance-based interventions were perceived as particularly positive across modules ( $46 \%$ of 89 feedback, $n=41$ ). Across the modules, open-ended questions indicated that contents were not always easy to understand $(34 \%, \mathrm{n}=30)$, not sufficiently individualised $(20 \%, \mathrm{n}=18)$ and too text intensive in overall amount $(21 \%, \mathrm{n}=19)$. 


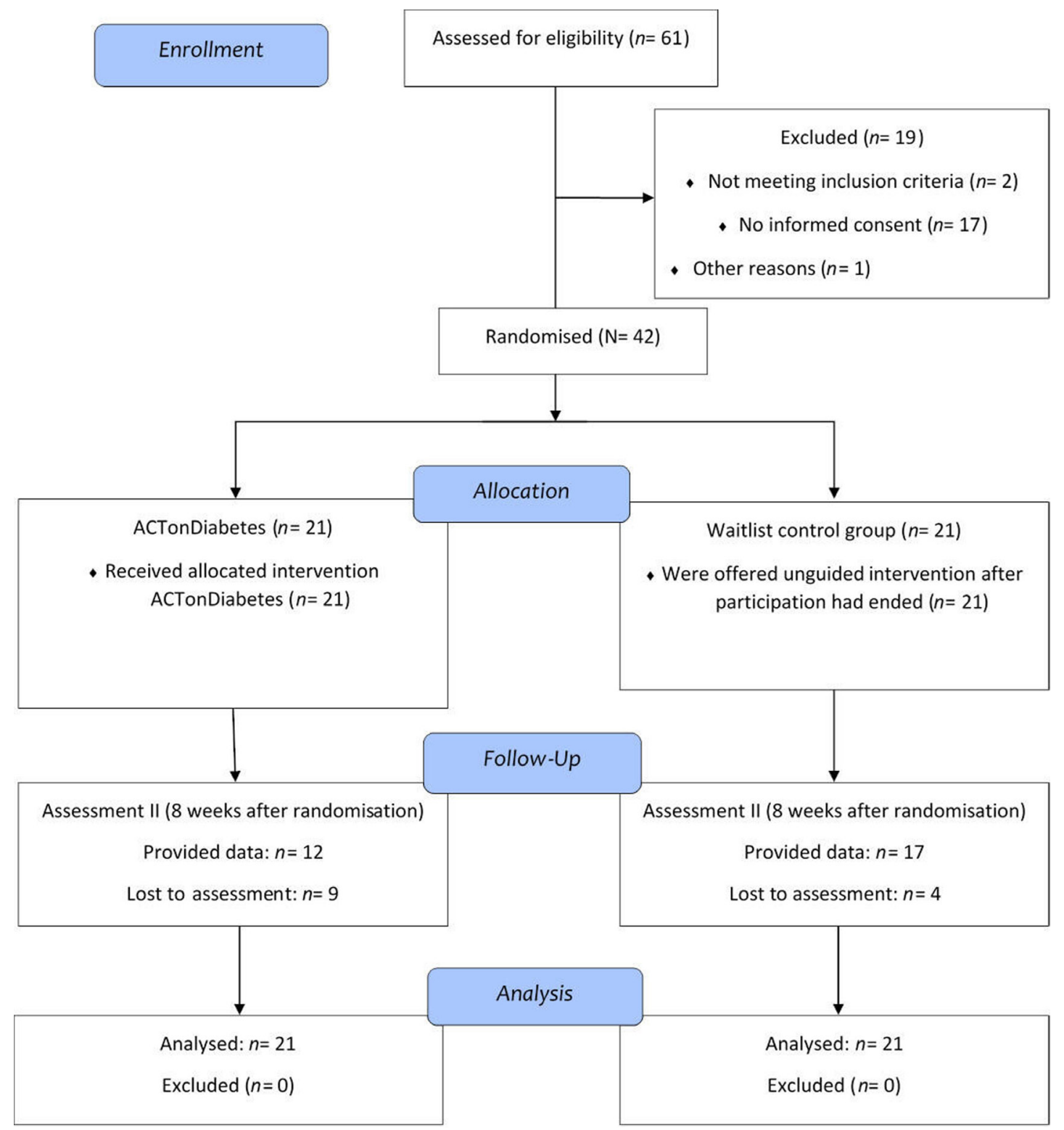

Figure 2 Participant flow.

\section{Negative effects}

At post-treatment, none of the participants of the EG indicated to feel worse than before ACTonDiabetes. About one-third of participants reported no change in their subjective well-being $(33 \%, \mathrm{n}=7)$, while two-thirds $(66 \%, \mathrm{n}=14)$ reported that their well-being improved since the start of the intervention. All participants who reported improvements attributed their experienced positive changes to the intervention. Four participants (14\%) reported to suffer more from past experiences than before the intervention; one of them attributed this change to the intervention, while the others attributed it to other circumstances. One person reported a more increased number of relationship conflicts than before the intervention. However, this was not attributed to the intervention. Two participants $(6.8 \%)$ reported worsened relationships with their families and three regarding friends $(10.3 \%)$ since the intervention, but none of them attributed these changes to the intervention. Four persons $(19 \%)$ of the EG worried that colleagues or peers might get to know about their participation in the study/ receiving treatment. Three persons $(10.3 \%)$ indicated to worry about possible future trouble with insurance; one of them attributed this to the intervention. Six persons $(20.7 \%)$ indicated to have more financial worries than before the intervention. One of them attributed this to the intervention. Eight persons $(27.5 \%)$ indicated feeling dependent on the intervention. Eleven persons $(37.8 \%)$ reported greater difficulties to make decisions on their own after finishing the intervention, but only one of them attributed this to the intervention. Finally, five persons $(17.2 \%)$ reported that they did not feel well for longer periods after attending the intervention but attributed this to other life circumstances.

Overall, $\mathrm{N}=16$ participants of the EG (76\%) reported at least one negative change in social, intrapersonal or 
Table 3 Baseline sample characteristics by group

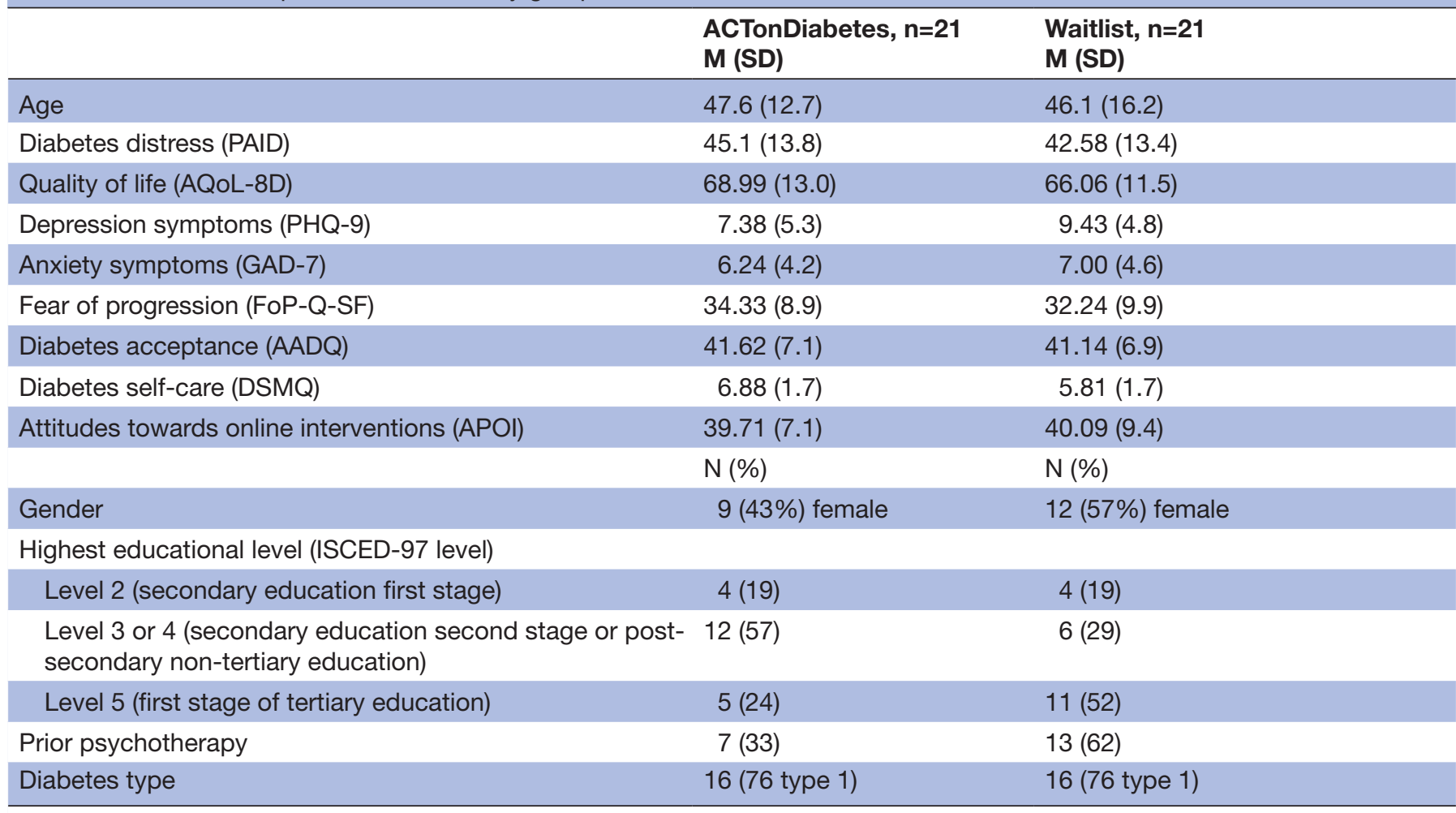

Data are $M(S D)$ or number (\%).

AADQ, Acceptance and Action Diabetes Questionnaire; APOI, Attitudes towards Psychological Online Interventions Questionnaire; AQoL8D, Assessment of Quality of Life 8-item Questionnaire; DSMQ, Diabetes Self-Management Questionnaire; FoP-Q-SF, Fear of Progression Questionnaire-Short Form; GAD-7, Generalized Anxiety Disorder 7-item Scale; ISCED-97, International Standard Classification of Education 1997; PAID, Problem Areas In Diabetes Scale; PHQ-9, Patient Health Questionnaire-9.

work-related aspects. Of them, $\mathrm{n}=6$ participants $(38 \%)$ attributed these experienced changes to the intervention. Thus, one-third of all treated participants experienced at least one negative change due to ACTonDiabetes.

\section{Intervention adherence}

Analyses on intervention adherence revealed that nine participants of the EG (43\%) completed all seven modules within 8 weeks after randomisation. Excluding participants who never started the intervention, from randomisation to post-treatment $57 \%(\mathrm{n}=10)$ dropped out before starting module 5 (figure 3). Eleven participants provided reasons for not starting or discontinuing: three participants indicated that participation was not useful to them, eight stated that they did not have enough time for further participation. Overall, $52 \%$ of all participants finished at least module 4 after 8 weeks.

\section{Changes in psychometric outcomes}

There was a significant difference between the groups regarding diabetes distress after the intervention (T2) favouring the EG (Cohen's $\mathrm{d}=0.65$, 95\% CI -1.27 to $-0.02, \mathrm{p}=0.042)$. The effect adjusted for the baseline value was $(b=-0.68,95 \%$ CI -1.36 to $0.02, p=0.048$, adjusted $\left.\mathrm{R}^{2}=0.17\right)$. Changes in the other assessed outcomes were non-significant between groups, however, all with a descriptive trend towards greater improvements in the EG (table 4).

\section{DISCUSSION}

This RCT evaluated the feasibility and potential effectiveness of an internet intervention to decrease elevated diabetes distress in people with type 1 or type 2 diabetes. To our knowledge, this is the first study that investigates an ACT-based internet intervention for this population. Participants reported elevated diabetes distress as well as depressive and anxiety symptoms, thus recruitment strategies reached people with an at least quantifiable level of psychological burden.

The participation rate in this study was at $71 \%$, indicating that the applied procedure to transfer eligible individuals into the study is appropriate. We reached female and male participants equally; however, the majority of the participants had type 1 diabetes. This is somewhat surprising as different studies show that both groups report equal burden due to diabetes. The imbalance may be in part explained by the recruitment strategies. That is, the overall number of members in identifiable self-organised social media groups with diabetes type 1 was $\mathrm{N}=15000$, while identifiable self-organised groups for diabetes type 2 comprised only about 1000 members. Furthermore, 


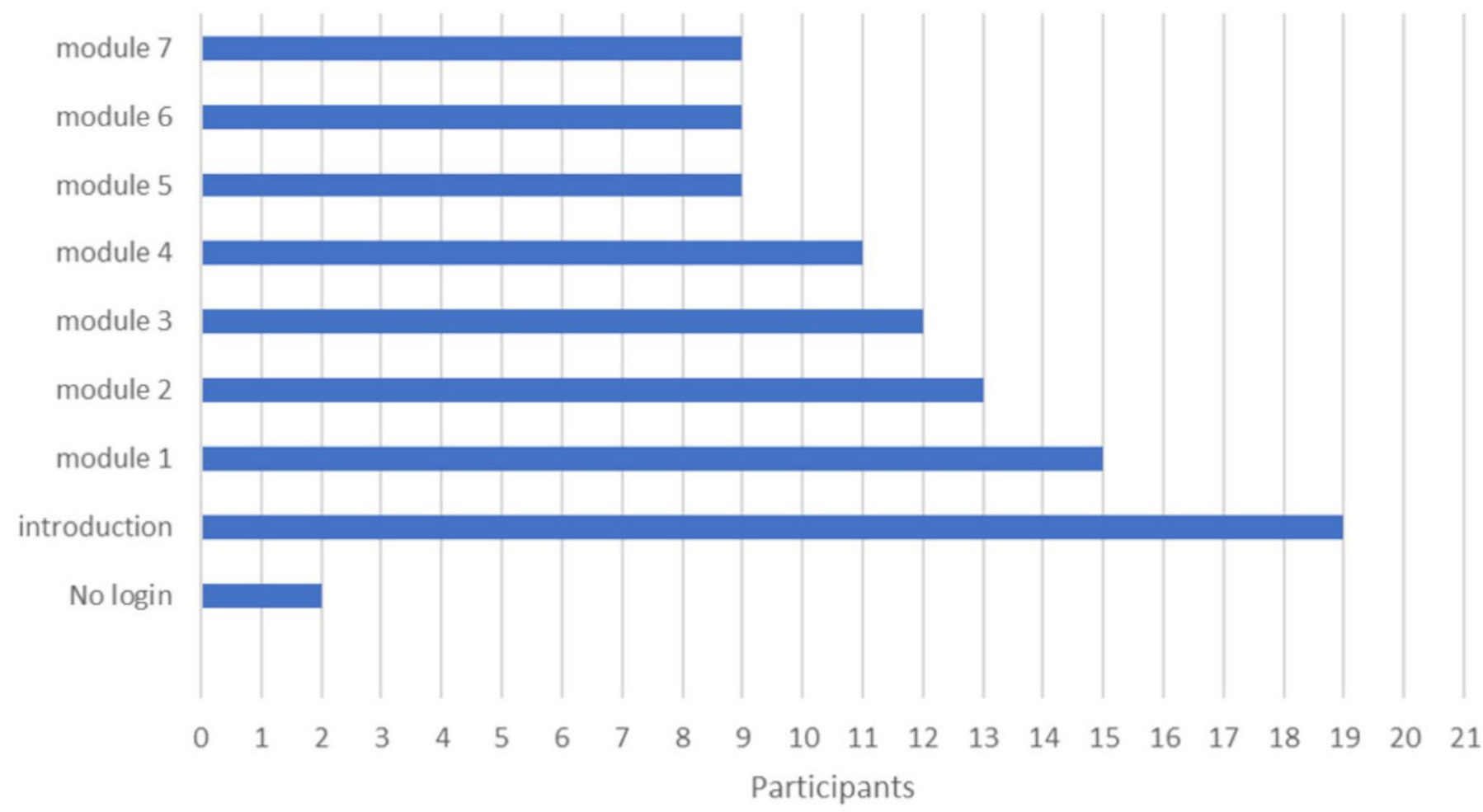

Figure 3 Intervention completion 8 weeks after randomisation.

many participants were recruited via specialised centres with an over-representation of people with type 1 diabetes compared with the primary care setting. Personal recommendation may have led to higher participation than advertisement only. Overall, the intervention seems to be particularly interesting for middle-aged persons of both sexes who treat their diabetes with insulin and are not currently undergoing psychotherapeutic treatment.

From randomisation to post-treatment, $30 \%$ of the participants dropped out, most of them discontinuing during the first half of the intervention. Only $43 \%$ of the participants finished all seven modules within 8 weeks after randomisation. However, $62 \%(\mathrm{n}=13)$ of the participants completed the intervention within 21 weeks after randomisation, suggesting that a slower treatment performance was preferred by some people. Although the dropout is comparable with other trials in the field, offline or online ${ }^{3379}$ future studies (including the planned full-scale trial) would benefit from adding mechanisms to foster adherence. Low intervention completion could limit the effectiveness of the intervention in a confirmatory trial. Guidance, SMS coaching and reminders might be useful techniques to keep participants involved ${ }^{8081}$ and should be further extended. A greater variety in presentation forms, helping to clarify contents and facilitating comprehension, could be experienced as positive and help to increase participants' adherence. ${ }^{82}$ Formative feedback on the intervention revealed that there should be less extensive and complex texts and better comprehensibility. Analyses of the processing time per module indicated that it took on average 24-39 min longer than expected to process through the intervention. However,
$75 \%$ of participants indicated that the processing time was just right for them. This inconsistency might be explained by possible breaks during working on the modules. The finding of long processing times suggests that the contents should not be extended per module in the further developed version of ACTonDiabetes. Another point that was raised by the participants concerns the individualisation of contents. Higher degrees of individualisation could be realised by adding diabetes-specific aspects of living with diabetes to the case vignettes (eg, by condensing the narratives throughout the intervention). This could help to better fit the intervention contents to the target population. Additionally, more individualisation could be achieved by expanding the space for individual life stories within the intervention. This could comprise personal writing like the development of illness narratives.

More comprehensibility could be achieved by strengthening interdisciplinary exchange, that is, with regard to text comprehension researchers. ${ }^{83}$ The use of written text as a medium for conveying contents should be limited in favour of other media and interactive materials like illustrations, videos and audio files. Another yet too little investigated and integrated factor is a positive experience and a gratification character when processing through internet interventions. Interventions could be further enriched by integrating token systems or serious games (eg, games with the primary purpose of knowledge transfer). ${ }^{84}$ To optimise the ACTonDiabetes intervention based on these findings, the amount of written text should be reduced per module by replacing it with video and audio materials. Also, optimising persuasiveness of ACTonDiabetes might improve adherence. ${ }^{85}$ 


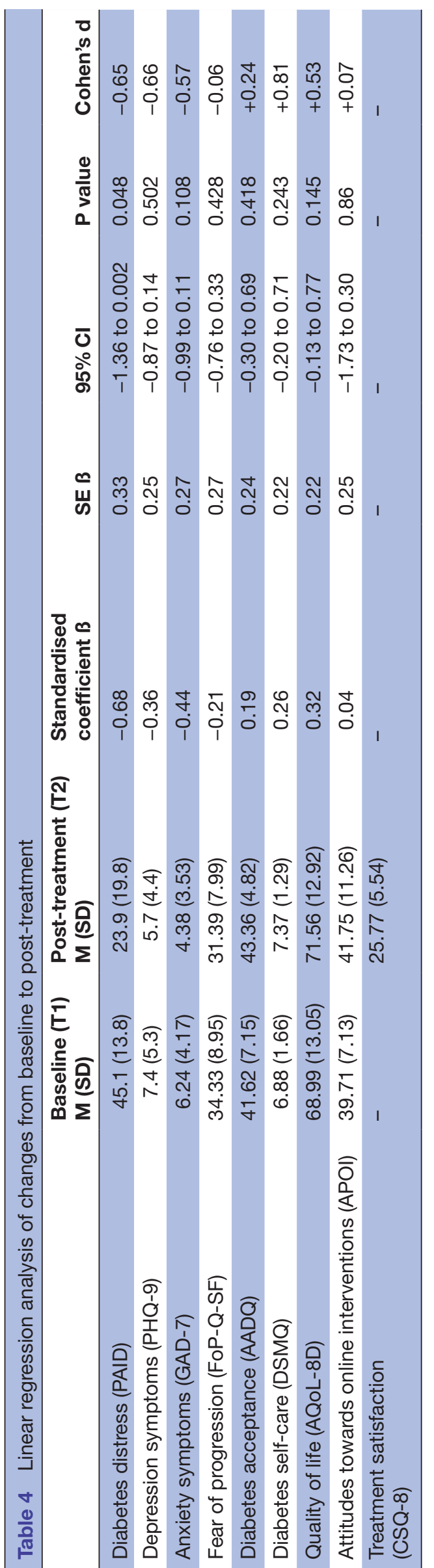

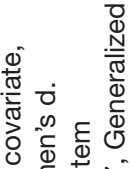
ช

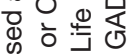
की

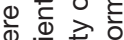
\. ๗) 정 क ఖ 응 늠 क ह

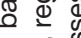
बิं 은 $\sum^{\infty} 0^{0}$ $\sum_{0}^{1}$

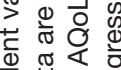
政

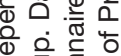
음 등 可语 동ㅎํ웜

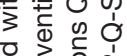

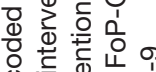

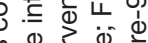
里导 음 क 尝

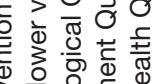
능응 웡 幽 离 is \& ब) 일

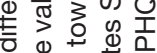
(1) क d Z先 0

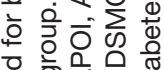
인원

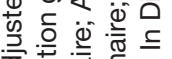

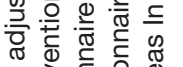

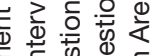
동

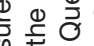

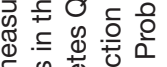
至 $\frac{\pi}{0}$

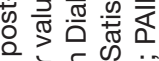
후웡

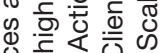

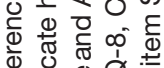
过 든

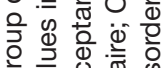
흔 은
The attitudes towards internet interventions were generally positive. More positive attitudes may be associated with increased effectiveness of internet interventions. ${ }^{86}$ Thus, providing more detailed information about ACTonDiabetes prior to the beginning of the intervention, or the inclusion of an acceptance-facilitating intervention at the start, might evoke more positive attitudes towards the internet-based treatment, hence increasing adherence and treatment effectiveness. ${ }^{6187-89}$

Satisfaction with the intervention was positive and comparable with results of psychological treatments in psychosomatic contexts. ${ }^{63}$ Participants reported nonsevere negative effects due to the intervention. This is consistent with the current literature suggesting that negative treatment effects should be expected and thus monitored carefully. ${ }^{90-92}$ Nevertheless, almost one-third of the participants reported at least one negative change which was attributed to the intervention. This points to the importance of considering possible negative side effects of ACTonDiabetes in a larger trial. To prevent such experiences, regular assessments should be implemented ${ }^{93}$ However, none of the participants of the EG indicated to feel worse due to the intervention. Future trials should measure both symptom deterioration and perceived negative effects during the treatment phase. ${ }^{93}$

To draw conclusions on effectiveness of the intervention regarding diabetes distress, it requires a larger study. The same holds true for potential effects on other intended outcomes like depression, anxiety and fear of progression. Likewise, effects on self-management and diabetes acceptance need to be evaluated in a larger study. Due to feasibility as primary outcome of this study, the small sample size as well as indications of inhomogeneity between the groups regarding prior psychotherapy/ counselling experiences and educational level, conclusions on effectiveness are not subject to this study.

Limitations of this study comprise the fact that all data are based on self-report. Future studies should at least rely on professional-assured diagnosis. Furthermore, the absence of $\mathrm{HbAlc}$ data is one of the main shortcomings of this study. Future studies should incorporate medical data like HbAlc values as the evaluation of potential changes in HbA1c might play a key role regarding the relevance of the intervention in diabetes care. Additionally, comorbid disorders could be assessed in future studies to achieve better insights into the physical conditions of participants.

Another limitation is that the study tested the EG against a waitlist CG with participants being a priori informed about the difference between the groups. Additionally, participants in the EG received the guided version of ACTonDiabetes while the CG received the unguided ACTonDiabetes intervention. Thus, effects of waiting for treatment and receiving ACTonDiabetes without guidance could have biased the data. For psychotherapy research in general, small effect sizes found in waitlist control groups suggest that testing a treatment against a waitlist might not be a very strict test. ${ }^{94}$ Future trials should use enhanced treatment-as-usual groups 
or an attention placebo control group to avoid these limitations.

Finally, the current sample was not recruited in a naturalistic setting, thus it may not reflect the real-life uptake of patients in the healthcare system. In order to investigate this, a pragmatic trial would have to be conducted which systematically recruits participants from routine care setting. In addition to this, no exact data were obtained on the number of people who were invited to participate. A future trial should address this shortcoming to allow the evaluation of the proportion of individuals reached from the potential eligible population.

Although generalisability of results is arguably limited, an important strength of this trial is the provision of deeper insights into evidence on internet-based mental health support for people with diabetes. A major strength is that we tested whether the intervention is feasible prior to implementing it on a larger scale. The intervention will be further optimised on the basis of the present findings prior to proceeding to the definitive trial.

A confirmatory trial will be needed to support the present preliminary findings and draw firm conclusions about treatment effects of ACTonDiabetes.

This paper may be fruitful for researchers planning studies or developing internet interventions for people with diabetes or other chronic conditions and comorbid psychological burden. ACT-based interventions constitute a promising approach in this context. New interventions for diabetes distress in people with type 1 or type 2 diabetes are needed. ACT could be particularly effective for people with diabetes as it focuses on the acceptance of unchangeable circumstances more specifically than standard CBT. The present results support that ACT-based interventions may be beneficial for people with diabetes. Strategies to foster adherence as well as content modifications according to the present results will be implemented to address key barriers to continued use and increase treatment effectiveness regarding diabetes distress.

ACTonDiabetes will be investigated in a subsequent full-scale trial. Trial registration number: DRKS00016738.

\section{Author affiliations}

${ }^{1}$ Department of Clinical Psychology and Psychotherapy, Institute of Psychology and Education, Ulm University, Ulm, Germany

${ }^{2}$ Research Institute of the Diabetes Academy Mergentheim, Diabetes Academy Bad Mergentheim, Bad Mergentheim, Germany

${ }^{3}$ German Center for Diabetes Research (DZD), München-Neuherberg, Germany

\section{Twitter Eileen Bendig @EileenBendig}

Acknowledgements We kindly thank Yannik Terhorst for verification of imputation procedures and statistics. We kindly thank Lena Storz for running the randomisation procedure. We kindly thank Agnes Geirhos and Pauline Meyer for e-coaching the participants. We kindly thank Lioba Fluhr for e-coaching participants and helping with the operative performance of the study. We kindly thank the people living with diabetes who gave their feedback in the development phase of the intervention.

Contributors EB, NB and HB designed and planned the study. ACTonDiabetes builds on ACTonPain (Jiaxi Lin) and was developed by the Department of Clinical Psychology and Psychotherapy at Ulm University (lead developer EB). The supervision was realised in a hierarchical structure with $\mathrm{HB}$ supervising EB who supervised project staff throughout the study. EB operatively performed the study. EB analysed and interpreted the data. EB drafted the manuscript. PA and AS critically revised the manuscript. AS additionally audited the manuscript for important intellectual content. All authors approved the final version to be published and agree to be accountable for all aspects of the work.

Funding The authors have not declared a specific grant for this research from any funding agency in the public, commercial or not-for-profit sectors.

Competing interests HB has received fees for lectures/workshops and consultancy fees from chambers of psychotherapists, psychological and medical associations and training institutes for psychotherapists as well as several third party-funded grants in the e-mental health context. All other authors report no conflicts of interest regarding this work.

Patient consent for publication Not required.

Ethics approval All procedures involved in the study are consistent with the generally accepted standards of ethical practice as approved by the ethics committee of the University of Ulm (file number 283/17).

Provenance and peer review Not commissioned; externally peer reviewed.

Data availability statement Data are available upon reasonable request.

Supplemental material This content has been supplied by the author(s). It has not been vetted by BMJ Publishing Group Limited (BMJ) and may not have been peer-reviewed. Any opinions or recommendations discussed are solely those of the author(s) and are not endorsed by BMJ. BMJ disclaims all liability and responsibility arising from any reliance placed on the content. Where the content includes any translated material, BMJ does not warrant the accuracy and reliability of the translations (including but not limited to local regulations, clinical guidelines, terminology, drug names and drug dosages), and is not responsible for any error and/or omissions arising from translation and adaptation or otherwise.

Open access This is an open access article distributed in accordance with the Creative Commons Attribution Non Commercial (CC BY-NC 4.0) license, which permits others to distribute, remix, adapt, build upon this work non-commercially, and license their derivative works on different terms, provided the original work is properly cited, appropriate credit is given, any changes made indicated, and the use is non-commercial. See: http://creativecommons.org/licenses/by-nc/4.0/.

\section{ORCID iDs}

Eileen Bendig http://orcid.org/0000-0001-6727-1751

Andreas Schmitt http://orcid.org/0000-0002-5913-1457

\section{REFERENCES}

1 Abajobir $\mathrm{AA}$, Abate $\mathrm{KH}$, et al. Global, regional, and national incidence, prevalence, and years lived with disability for 328 diseases and injuries for 195 countries, 1990-2016: a systematic analysis for the global burden of disease study 2016 . The Lancet 2017;390:1211-59 https://linkinghub.elsevier.com/retrieve/pii/ S0140673617321542 doi:10.1016/S0140-6736(17)32154-2

2 Tönnies T, Röckl S, Hoyer A, et al. Projected number of people with diagnosed type 2 diabetes in Germany in 2040. Diabet Med 2019;36:1217-25.

3 Lancet T. The diabetes pandemic. The Lancet. 2011;378. :99.

4 Seaquist ER. Addressing the burden of diabetes. J Am Med Assoc 2014;311:2267-8.

5 Hermanns N, Bremmer MA, Snoek FJ. Diabetes Distress. In: Ismail K, Barthel A, Bornstein SR, et al, eds. Depression and type 2 diabetes. OUP Oxford, 2018.

6 Kulzer B, Lüthgens B, Landgraf R, et al. Diabetesbezogene Belastungen, Wohlbefinden und Einstellung von Menschen MIT diabetes. Der Diabetol 2015;11:211-8.

7 Fisher L, Polonsky WH, Hessler DM, et al. Understanding the sources of diabetes distress in adults with type 1 diabetes. $J$ Diabetes Complications 2015;29:572-7.

8 Ismail K, Winkley K, Rabe-Hesketh S. Systematic review and meta-analysis of randomised controlled trials of psychological interventions to improve glycaemic control in patients with type 2 diabetes. Lancet 2004;363:1589-97.

9 Winkley K, Ismail K, Landau S, et al. Psychological interventions to improve glycaemic control in patients with type 1 diabetes: systematic review and meta-analysis of randomised controlled trials. BMJ 2006;333:65.

10 Fisher EB, Thorpe CT, DeVellis BM, et al. And diabetes management: a systematic review and appraisal. Diabetes Educ 2007;33:1080-103.

11 Fisher L, Hessler D, Glasgow RE, et al. REDEEM: a pragmatic trial to reduce diabetes distress. Diabetes Care 2013;36:2551-8. 
12 Perrin NE, Davies MJ, Robertson N, et al. The prevalence of diabetes-specific emotional distress in people with type 2 diabetes: systematic review and meta-analysis. Diabet Med 2017;34:1508-20.

13 Psychosocial care for people with diabetes: a position statement of the American diabetes association. Diabetes Care 2016;39:40 http:// care.diabetesjournals.org/content/39/12/2126.full-text.pdf

14 Peyrot M, Rubin RR, Lauritzen T, et al. Psychosocial problems and barriers to improved diabetes management: results of the crossnational diabetes attitudes, wishes and needs (dawn) study. Diabet Med 2005;22:1379-85.

15 Fisher L, Hessler D, Polonsky W, et al. Diabetes distress in adults with type 1 diabetes: prevalence, incidence and change over time. $J$ Diabetes Complications 2016;30:1123-8.

16 Fisher L, Mullan JT, Arean P, et al. Diabetes distress but not clinical depression or depressive symptoms is associated with glycemic control in both cross-sectional and longitudinal analyses. Diabetes Care 2010;33:23-8.

17 Fisher L, Glasgow RE, Strycker LA. The relationship between diabetes distress and clinical depression with glycemic control among patients with type 2 diabetes. Diabetes Care 2010;33:1034-6.

18 Ehrmann D, Kulzer B, Haak T, et al. Longitudinal relationship of diabetes-related distress and depressive symptoms: analysing incidence and persistence. Diabet Med 2015;32:1264-71 http://doi. wiley.com/ doi:10.1111/dme.12861

19 Young-Hyman D, de Groot M, Hill-Briggs F, et al. Psychosocial care for people with diabetes: a position statement of the American diabetes association. Diabetes Care 2016;39:2126-40 https://www. researchgate.net/profile/Wilma_Scholte_Op_Reimer/publication/ 278407643_The_Fifth_Joint_Task_Force_of_the_European_Society_ of_Cardiology_and_Other_Societies_on_Cardiovascular_Disease_ Prevention_in_Clinical_Practice_constituted_by_representative doi:10.2337/dc16-2053

20 Kulzer B, Albus C, Herpertz S. Psychosoziales und diabetes (Teil 1). Diabetol und Stoffwechsel 2013;8:242 http://www.thieme-connect. de/DOI/DOI

21 Kulzer B, Albus C, Herpertz S. Psychosoziales und diabetes (Teil 2). Diabetol und Stoffwechsel 2013;8:324 http://www.thieme-connect. de/DOI/DOI

22 Aerzteblatt D. Psychosoziale Aspekte bei diabetes mellitus: Versorgungsbedarf Stark unterschätzt 2005.

23 Groschwitz RC, Fegert JM, Plener PL. Psychiatrische und psychotherapeutische Versorgung in Deutschland. Ergebnisse einer repräsentativen Umfrage. Psychotherapeut 2017;62:12-17.

24 Andrade LH, Alonso J, Mneimneh Z, et al. Barriers to mental health treatment: results from the who world mental health surveys. Psychol Med 2014;44:1303-17.

25 Sturt J, Dennick K, Due-Christensen M, et al. The detection and management of diabetes distress in people with type 1 diabetes. Curr Diab Rep 2015;15:1-14.

26 Bendig E, Bauereiß N, Ebert DD, et al. Internet- based interventions in chronic somatic disease. Dtsch Arztebl Int 2018;115:66 https:// www.aerzteblatt.de/ doi:10.3238/arztebl.2018.0659

27 Paganini S, Ebert DD, Lin J, et al. Internet- und Mobilebasierte Interventionen bei psychischen Störungen. NeuroTransmitter 2016;1:48-53.

28 Nobis S, Lehr D, Ebert DD, et al. Efficacy and cost-effectiveness of a web-based intervention with mobile phone support to treat depressive symptoms in adults with diabetes mellitus type 1 and type 2: design of a randomised controlled trial. BMC Psychiatry 2013;13:306 http://www.ncbi.nlm.nih.gov/pubmed/24238346 doi:10.1186/1471-244X-13-306

29 van Bastelaar KMP, Pouwer F, Cuijpers P, et al. Web-Based depression treatment for type 1 and type 2 diabetic patients: a randomized, controlled trial. Diabetes Care 2011;34:320-5.

30 Barak A, Klein B, Proudfoot JG. Defining internet-supported therapeutic interventions. Ann Behav Med 2009;38:4-17 http://www. ncbi.nlm.nih.gov/pubmed/19787305 doi:10.1007/s12160-009-91307

31 van Beugen S, Ferwerda M, Hoeve D, et al. Internet-Based cognitive behavioral therapy for patients with chronic somatic conditions: a meta-analytic review. J Med Internet Res 2014;16. doi:10.2196/ jmir.2777. [Epub ahead of print: Available from] https://www.jmir.org/ 2014/3/e88/

32 Baumeister H, Reichler L, Munzinger M, et al. The impact of guidance on Internet-based mental health interventions - a systematic review. Internet Interv 2014;1:205-15 http://linkinghub. elsevier.com/retrieve/pii/S2214782914000244 doi:10.1016/j. invent.2014.08.003

33 Carlbring P, Andersson G, Cuijpers P, et al. Internet-Based vs. face-to-face cognitive behavior therapy for psychiatric and somatic disorders: an updated systematic review and meta-analysis. Cogn Behav Ther 2018;47:1-18.

34 Bian RR, Piatt GA, Sen A, et al. The effect of Technology-Mediated diabetes prevention interventions on weight: a meta-analysis. J Med Internet Res 2017;19:e76.

35 Jennings CA, Vandelanotte C, Caperchione CM, et al. Effectiveness of a web-based physical activity intervention for adults with type 2 diabetes-a randomised controlled trial. Prev Med 2014;60:33-40.

36 Hou C, Carter B, Hewitt J, et al. Do mobile phone applications improve glycemic control $(\mathrm{HbA} 1 \mathrm{c})$ in the self-management of diabetes? A systematic review, meta-analysis, and grade of 14 randomized trials. Diabetes Care 2016;39:2089-95.

37 Palmer M, Sutherland J, Barnard S, et al. The effectiveness of smoking cessation, physical activity/diet and alcohol reduction interventions delivered by mobile phones for the prevention of non-communicable diseases: a systematic review of randomised controlled trials. PLoS One 2018;13:e0189801.

38 Black N, Mullan B, Sharpe L. Computer-delivered interventions for reducing alcohol consumption: meta-analysis and meta-regression using behaviour change techniques and theory. Health Psychol Rev 2016;10:341-57

39 Ebert DD, Nobis S, Lehr D, et al. The 6-month effectiveness of Internet-based guided self-help for depression in adults with type 1 and 2 diabetes mellitus. Diabet Med 2017;34:99-107 http://doi.wiley. com/ doi:10.1111/dme.13173

40 Nobis S, Lehr D, Ebert DD, et al. Efficacy of a web-based intervention with mobile phone support in treating depressive symptoms in adults with type 1 and type 2 diabetes: a randomized controlled trial. Diabetes Care 2015;38:776-83 http://www.ncbi.nlm.nih.gov/ pubmed/25710923 doi:10.2337/dc14-1728

41 Ebert DD, Nobis S, Lehr D, et al. The 6-month effectiveness of internet-based guided self-help for depression in adults with type 1 and 2 diabetes mellitus. Diabet Med 2017;34:99-107 http://doi.wiley. com/ doi:10.1111/dme.13173

42 Andersson G. The Internet and CBT. CRC Press, 2014.

43 Hayes SC. Acceptance and commitment therapy, relational frame theory, and the third wave of behavioral and cognitive therapies. Behav Ther 2004;35:639-65.

44 Hayes SC, Smith SX. Get Out of Your Mind \& Into Your Life : the New Acceptance \& Commitment Therapy. New Harbinger Publications, 2006: 206 p.

45 Gregg JA, Callaghan GM, Hayes SC, et al. Improving diabetes self-management through acceptance, mindfulness, and values: a randomized controlled trial. J Consult Clin Psychol 2007;75:336-43.

46 Shayeghian Z, Hassanabadi H, Aguilar-Vafaie ME, et al. A randomized controlled trial of acceptance and commitment therapy for type 2 diabetes management: the moderating role of coping styles. PLoS One 2016;11:e0166599.

47 Maghsoudi Z, Razavi Z, Razavi M, et al. Efficacy of acceptance and commitment therapy for emotional distress in the elderly with type 2 diabetes: a randomized controlled trial. Diabetes Metab Syndr Obes 2019;12:2137-43.

48 Amsberg S, Wijk I, Livheim F, et al. Acceptance and commitment therapy (act) for adult type 1 diabetes management: study protocol for a randomised controlled trial. BMJ Open 2018;8:22234.

49 Lin J, Paganini S, Sander L, et al. An Internet-based intervention for chronic pain. Dtsch Aerzteblatt Online 2017:114:681-8.

50 Lin J, Paganini S, Sander L. An Internet-based intervention for chronic pain: a three-arm randomized controlled study of the effectiveness of guided and unguided acceptance and. ncbi.nlm.nih. gov..

51 Paganini S, Lin J, Kählke F, et al. A guided and unguided internetand mobile-based intervention for chronic pain: health economic evaluation alongside a randomised controlled trial. BMJ Open 2019:9:1-13.

52 Eldridge SM, Chan CL, Campbell MJ. Consort 2010 statement: extension to randomised pilot and feasibility trials. BMJ 2016;355:32

53 Thabane L, Ma J, Chu R, et al. A tutorial on pilot studies: the what, why and how. BMC Med Res Methodol 2010;10:1-10.

54 Siddiqi A-E-A, Sikorskii A, Given CW, et al. Early participant attrition from clinical trials: role of trial design and logistics. Clin Trials 2008;5:328-35.

55 Choi PT, Beattie WS, Bryson GL, et al. Effects of neuraxial blockade may be difficult to study using large randomized controlled trials: the perioperative epidural trial (poet) pilot study. PLoS One 2009;4:e4644 https://dx.plos.org/ doi:10.1371/journal.pone.0004644

56 Bowen DJ, Kreuter M, Spring B, et al. How we design feasibility studies. Am J Prev Med 2009;36:452-7. doi:10.1016/j. amepre.2009.02.002

57 Schröder J, Sautier L, Kriston L, et al. Development of a questionnaire measuring attitudes towards psychological online 
Interventions-the APOI. J Affect Disord 2015;187:136-41. doi:10.1016/j.jad.2015.08.044

58 Ladwig I, Rief W, Nestoriuc Y. Welche Risiken und Nebenwirkungen hat Psychotherapie? - Entwicklung des Inventars zur Erfassung Negativer Effekte von Psychotherapie (INEP). Verhaltenstherapie 2014;24:252-63 https://www.karger.com/Article/FullText/367928 doi:10.1159/000367928

59 Schmidt J, Nübling R. ZUF-8. Fragebogen zur Patientenzufriedenheit. In: Brähler E, Schumacher J, Strauß B, eds. Diagnostische Verfahren in Der Psychotherapie. Göttingen: Hogrefe, 2002: 392-6.

60 Jimison H, Gorman P, Woods S, et al. Barriers and Drivers of Health Information Technology Use for the Elderly, Chronically III, and Underserved - PubMed. Evid Reports/Technology Assessments 2008;175. [Epub ahead of print: Available from] https://pubmed.ncbi. nlm.nih.gov/19408968/

61 Ebert DD, Berking M, Cuijpers P. Increasing the acceptance of Internet-based mental health interventions in primary care patients with depressive symptoms. A randomized controlled trial. J Affect Disord 2015;176:17 http://www.ncbi.nlm.nih.gov/pubmed/25682378

62 Schröder J, Berger T, Meyer B, et al. Attitudes towards Internet interventions among Psychotherapists and individuals with mild to moderate depression symptoms. Cognit Ther Res 2017;41:745-56 http://link.springer.com/ doi:10.1007/s10608-017-9850-0

63 Kriz D, Nübling R, Steffanowski A. Patients' satisfaction in inpatient rehabilitation. Psychometrical evaluation of the ZUF-8 based on a multicenter sample of different indications. Zeitschrift für Medizinische Psychol 2008;17:67-79.

64 Polonsky WH, Anderson BJ, Lohrer PA, et al. Assessment of diabetes-related distress. Diabetes Care 1995;18:754-60.

65 Hermanns N, Kulzer B, Krichbaum M, et al. How to screen for depression and emotional problems in patients with diabetes: comparison of screening characteristics of depression questionnaires, measurement of diabetes-specific emotional problems and standard clinical assessment. Diabetologia 2006;49:469-77.

66 Kroenke K, Spitzer RL, Williams JB. The PHQ-9: validity of a brief depression severity measure. J Gen Intern Med 2001;16:606-13.

67 Spitzer RL, Kroenke K, Williams JBW, et al. A brief measure for assessing generalized anxiety disorder: the GAD-7. Arch Intern Med 2006;166:1092-7.

68 Schmitt A, Gahr A, Hermanns N, et al. The diabetes selfmanagement questionnaire (DSMQ): development and evaluation of an instrument to assess diabetes self-care activities associated with glycaemic control. Health Qual Life Outcomes 2013;11:138.

69 Schmitt A, Gahr A, Hermanns N, et al. AADQ : Evaluation der deutschen Fassung des Fragebogens. Diabetes, Stoffwechsel und Herz 2013;22:9-15.

70 Richardson J, lezzi A, Khan MA, et al. Validity and reliability of the Assessment of Quality of Life (AQoL)-8D multi-attribute utility instrument. Patient 2014:7:85-96.

71 Berg P, Book K, Dinkel A, et al. Progredienzangst bei chronischen Erkrankungen. PPmP Psychother Psychosom Medizinische Psychol 2011;61:32-7.

72 Avery KNL, Williamson PR, Gamble C, et al. Informing efficient randomised controlled trials: exploration of challenges in developing progression criteria for internal pilot studies. BMJ Open 2017;7. doi:10.1136/bmjopen-2016-013537. [Epub ahead of print: Available from] http://www.ncbi.nlm.nih.gov/pubmed/28213598

73 R Core Team. R: A Language and Environment for Statistical Computing [Internet. Vienna, Austria, 2017. https://www.r-project.org

74 van Buuren S, Groothuis-Oudshoorn K. Mice: multivariate imputation by Chained. $J$ Stat Softw 2011;45:1-68.

75 Enders CK. Applied missing data analysis. Guilford press, 2010.

76 van Buuren S, Boshuizen HC, Knook DL. Multiple imputation of missing blood pressure covariates in survival analysis. Stat Med 1999;18:681-94.
77 Rubin D. Multiple imputation after 18+ years. J Am Stat Assoc 1996;91:473-89.

78 Rubin D. Multiple imputation for nonresponse in surveys. John Wiley \& Sons, 2004.

79 Melville KM, Casey LM, Kavanagh DJ. Dropout from Internetbased treatment for psychological disorders. Br J Clin Psychol 2010:49:455-71.

80 Brouwer W, Kroeze W, Crutzen R, et al. Which intervention characteristics are related to more exposure to internet-delivered healthy lifestyle promotion interventions? A systematic review. J Med Internet Res 2011;13. doi:10.2196/jmir.1639. [Epub ahead of print: Available from] http://www.ncbi.nlm.nih.gov/pubmed/21212045

81 Fry JP, Neff RA. Periodic prompts and reminders in health promotion and health behavior interventions: systematic review. J Med Internet Res 2009;11:e16.

82 Ebert DD, Van Daele T, Nordgreen T, et al. Internet and mobile-based psychological interventions: applications, efficacy and potential for improving mental health. A report of the EFPA e-health Taskforce. Eur Psychol 2018;23:167-87.

83 Zwaan RA, Singer M, Comprehension T. Handbook of discourse processes. In: Graesser AC, Gernsbacher MA, Goldman SR, eds. Lawrence Erlbaum publishers, 2003: 83-121.

84 Schrader C, Brich J, Frommel J. Rising to the challenge: an emotiondriven approach toward adaptive serious games. in: serious games and Edutainment applications: volume II. Springer International Publishing, 2017: 3-28.

85 Baumeister H, Kraft R, Baumel A. Persuasive e-health design for behavior change. Cham: Springer, 2019: 261-76.

86 Schröder J, Berger T, Meyer B, et al. Impact and change of attitudes toward Internet interventions within a randomized controlled trial on individuals with depression symptoms. Depress Anxiety 2018;35:421-30.

87 Baumeister H, Nowoczin L, Lin J, et al. Impact of an acceptance facilitating intervention on diabetes patients' acceptance of Internet-based interventions for depression: a randomized controlled trial. Diabetes Res Clin Pract 2014;105:30-9 http:// www.ncbi.nlm.nih.gov/pubmed/24862240 doi:10.1016/j. diabres.2014.04.031

88 Baumeister $\mathrm{H}$, Seifferth $\mathrm{H}$, Lin J, et al. Impact of an acceptance facilitating intervention on patients' acceptance of Internet-based pain interventions: a randomized controlled trial. Clin J Pain 2015:31:528-35.

89 Lin J, Faust B, Ebert DD, et al. A Web-Based Acceptance-Facilitating Intervention for Identifying Patients' Acceptance, Uptake, and Adherence of Internet- and Mobile-Based Pain Interventions: Randomized Controlled Trial. J Med Internet Res 2018;20:18. doi:10.2196/jmir.9925

90 Rozental A, Castonguay L, Dimidjian S, et al. Negative effects in psychotherapy: commentary and recommendations for future research and clinical practice. BJPsych Open 2018;4:307-12.

91 Herzog P, Lauff S, Rief W, et al. Assessing the unwanted: a systematic review of instruments used to assess negative effects of psychotherapy. Brain Behav 2019;9:e01447.

92 Boettcher J, Rozental A, Andersson G, et al. Side effects in Internetbased interventions for social anxiety disorder. Internet Interv 2014;1:3-11.

93 Rozental A, Andersson G, Boettcher J, et al. Consensus statement on defining and measuring negative effects of internet interventions. Internet Interv 2014;1:12-19 http://linkinghub.elsevier.com/retrieve/ pii/S2214782914000037 doi:10.1016/j.invent.2014.02.001

94 Steinert C, Stadter K, Stark R, et al. The effects of waiting for treatment: a meta-analysis of Waitlist control groups in randomized controlled trials for social anxiety disorder. Clin Psychol Psychother 2017:24:649-60.

95 Kanfer FH, Saslow G. Behavioral analysis: an alternative to diagnostic classification. Arch Gen Psychiatry 1965;12:529-38. 